Check for updates

Cite this: RSC Adv., 2019, 9, 27318

Received 22nd June 2019

Accepted 24th August 2019

DOI: $10.1039 / c 9 r a 04682 h$

rsc.li/rsc-advances

\title{
Pyrazolo-fused 4-azafluorenones as key reagents for the synthesis of fluorescent dicyanovinylidene- substituted derivatives $\uparrow$
}

\begin{abstract}
Jessica Orrego-Hernández, ${ }^{a}$ Carolina Lizarazo, ${ }^{a}$ Justo Cobo ${ }^{\mathrm{b}}$ and Jaime Portilla (DD *a
A green process to access pyrazolo-fused 4-azafluorenones (indeno[1,2-b]pyrazolo[4,3-e]pyridines, IPP) $4 a-x$ via the three-component reaction between indan-1,3-dione (1), benzaldehydes 2 and 5-amino-1arylpyrazoles 3 is described. These compounds were successfully used as precursors of the novel dicyanovinylidene derivatives $7 a-d$ containing different acceptor (A) or donor (D) aryl groups at position 4 of its fused system. The structures of products obtained ( $4 a-x$ and $7 a-d)$ were determined based on NMR experiments, HRMS analysis, and X-ray diffraction studies for 7b. The photophysical and computational studies of $7 a-d$ showed that these products are modulable ICT fluorophores, even some preliminary tests revealed that these compounds could be used as fluorescent chemodosimeters for cyanide detection.
\end{abstract}

\section{Introduction}

In recent years, the development of a highly efficient atom and step economic synthesis of fused aza-heterocycles to yield biologically active compounds has been actively pursued, and thus has become an important area of research in organic and medicinal chemistry. ${ }^{1-3}$ In particular, pyrazolo[3,4-b]pyridines (PP) are of biomedical importance and have been extensively studied for their broad biological activity. ${ }^{4-6}$ Likewise, indeno $[1,2-b]$ pyridines (4-azafluorenones, IP) have shown potential as anticancer, antioxidant, antihistamine and antidepressant agents. ${ }^{7,8}$ Both 4 -azafluorenones and pyrazolo[3,4-b]pyridines have found applications in materials science due to their amazing photophysical properties. ${ }^{9,10}$ Thus, the development of efficient methods for the synthesis and functionalization of fused systems of these two structural moieties (i.e., pyrazolofused 4-azafluorenones) is highly desirable (Fig. 1).

Numerous approaches for the synthesis of $\mathbf{P P}^{11,12}$ and their fused derivatives have been reported, ${ }^{13,14}$ those reactions involved the interaction of 1,3-bis-electrophilic compounds with $\mathrm{N}$-substituted 5 -aminopyrazoles. ${ }^{11-14}$ Moreover, multicomponent reactions (MCRs) are used in the synthesis of these compounds by the formation in situ of the bis-

${ }^{a}$ Bioorganic Compounds Research Group, Department of Chemistry, Universidad de los Andes, Carrera 1 No.18A-10, Bogotá 111711, Colombia. E-mail: jportill@uniandes. edu.co

${ }^{b}$ Departamento de Quimica Orgánica e Inorgánica, Universidad de Jaén, 23071 Jaén, Spain

† Electronic supplementary information (ESI) available: Experimental, characterization data, X-ray structures of $7 \mathbf{b}$ and NMR spectra of $4 \mathbf{a}-\mathbf{x}, 5 \mathbf{5 a}, \mathbf{6 h}$, 7a-d. CCDC 1886021. For ESI and crystallographic data in CIF or other electronic format see DOI: 10.1039/c9ra04682h electrophilic intermediate. This approach has been widely used in diversity-oriented synthesis (DOS) of biologically active heterocyclic compounds. ${ }^{15,16}$ However, there are few reports addressing the preparation of indeno-fused PP, and those synthetic procedures have some limitations (e.g., moderate yields, the use of additives or catalysts, ionic liquids as solvent, and reduced substrate scope). Indeed, the most remarkable limitation is the substrate scope, since reactions have been restricted to the use of 5-amino-1-phenyl-3-methylpyrazole (3a) with only a few reported exceptions (Scheme 1a). ${ }^{17-20}$ One of the few examples using a different amine was done from our group, we reported an initial study of the crystal structure of indeno $[1,2-b]$ pyrazolo[4,3-e]pyridines (IPP) $\mathbf{4 p}$ and $\mathbf{4 u}$ which was prepared by the three-component reaction between indan-1,3dione (1), benzaldehydes 2a or 2f, and 5-amino-3-tert-butyl-1(4-chlorophenyl)pyrazole (3c) in good yields. Those reactions were achieved at $80^{\circ} \mathrm{C}$ under microwave irradiation (MW) using triethylamine $\left(\mathrm{Et}_{3} \mathrm{~N}\right)$ as a catalyst in water (Scheme $\left.1 \mathrm{~b}\right) .{ }^{21}$

Continuing with the development of synthetic methods to obtain pyrazole-fused aza-heterocycles ${ }^{22-25}$ along with our

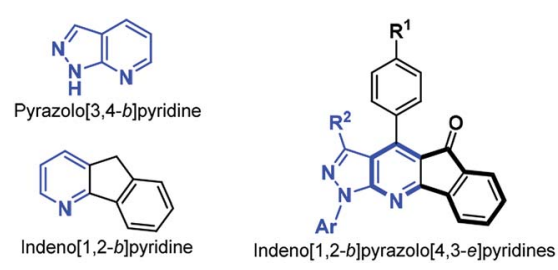

Fig. 1 Pyrazolo[3,4-b]pyridine, indeno[1,2-e]pyridine and their combined-fused derivatives. The 4-azafluorene moiety is remarked in a bold line. 


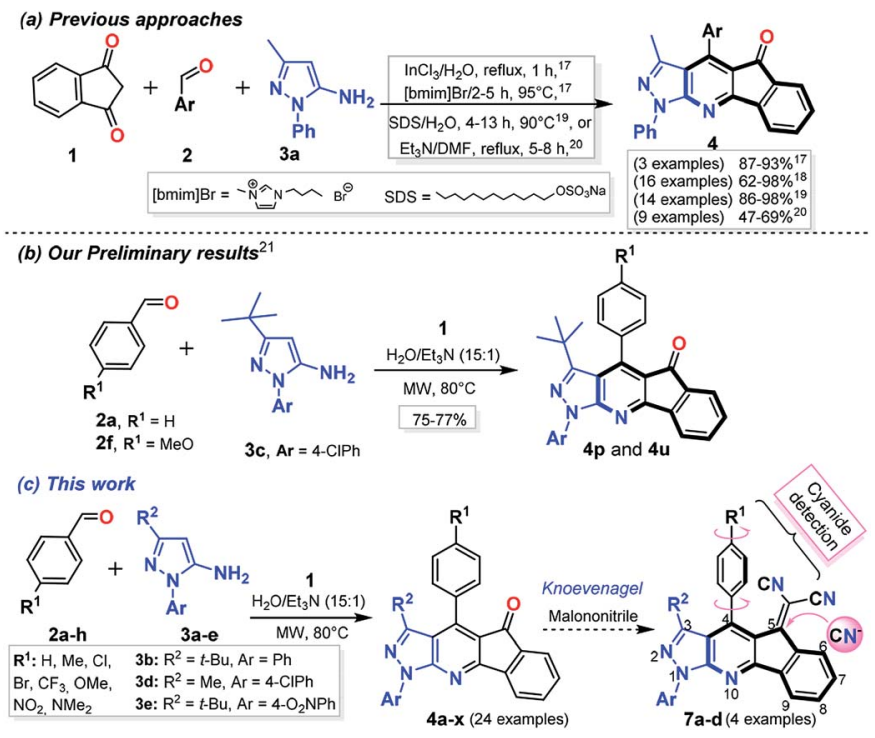

Scheme 1 Synthesis of indeno[1,2-b]pyrazolo[4,3-e]pyridin-5-ones 4 and $4 a-x$.

interest to improve the scope of our preliminary results by using different starting 5 -aminopyrazoles, we report an extension of the MW-assisted synthesis of indeno[1,2- $b]$ pyrazolo[4,3-e]pyridines $4 \mathbf{a}-\mathbf{x}$ via the respective multicomponent reaction using the 5-amino-1-arylpyrazoles $3 \mathbf{a}-\mathbf{e}$ of diverse reactivity. It is important to note that the electron-withdrawing aryl groups at position 1 of the starting amines (i.e., 3c-e) decrease its reactivity towards cyclocondensation reactions, ${ }^{22}$ which would complicate the synthesis of some IPP $\mathbf{4 a - x}$ (Scheme 1c). In addition, IPP derivatives have a structural analogy with the fluorene core (Fig. 1), whose derivatives have important fluorescent properties with applications on the design of OLEDs and organic transistors. ${ }^{26-29}$ Due to the structural features of ketones $\mathbf{4 a - x}$, the post-functionalization reactions and the physicochemical study of their respective functional products are of great interest. The synthesis of the dicyanovinylidene derivatives $\mathbf{7 a - d}$ and their photophysical properties with an initial application in fluorescent probes were also included, which has been an area that has been recently studied in our group (Scheme 1c). ${ }^{22,30-33}$

\section{Results and discussion}

\subsection{Synthesis}

Starting from our preliminary and promising results of the synthesis of IPP $\mathbf{4 p}$ and $\mathbf{4 u},{ }^{21}$ we have studied a range of reaction using different starting 5 -aminopyrazoles $3 \mathbf{a}-\mathbf{e}$ and benzaldehydes 2a-h (Scheme 1c). Our study of these polycyclic compounds synthesis began by optimization of the reaction conditions (conventional or MW heating, solvent, base, temperature, and reaction time) by using as a model reaction an equimolar mixture of indan-1,3-dione (1), benzaldehyde (2a) and 5-amino-1-phenyl-3-methyl-1 $H$-pyrazol (3a). As expected, the reaction gave the desired IPP $\mathbf{4 a}$ in good yield under the

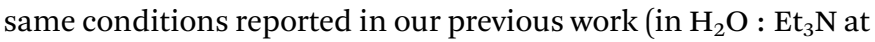

$80{ }^{\circ} \mathrm{C}$ for $10 \mathrm{~min}$ under $\mathrm{MW}^{21}$ ), and yield was improved by prolonging the reaction time, but not the temperature (Table 1 , entries 1-3). Heating under reflux in different solvents using triethylamine as a catalyst offered the product $4 \mathbf{a}$ but in low to moderate yields (Table 1, entries 4-6). We found out that higher temperatures favors formations of the IPP $\mathbf{4 a},{ }^{20}$ while lower temperatures result in low yield (Table 1 , entry 5 vs. 6). ${ }^{34}$

When the reaction was carried out without base or other bases $\left(\mathrm{KOH}\right.$ or $\left.\mathrm{K}_{2} \mathrm{CO}_{3}\right)$ in water or ethanol under $\mathrm{MW}$, the formation of $4 \mathbf{a}$ was diminished (Table 1, entries 7-10). Consequently, the optimal conditions were set to obtain $4 \mathbf{a}$ in a similar way to those reported in our preliminary study (Table 1, entry 2). ${ }^{21}$ In general, low yields for the formation of $\mathbf{4 a}$ were observed when ethanol was used as a solvent (Table 1, entries 6 and 8). These conditions are closely related to those used for pyrazolo[5,1- $b]$ quinazolines synthesis reported by Chebanov et al. (by using dimedone, arylaldehydes and a $N H$-pyrazole). ${ }^{35}$ On the other hand, when the reaction was carried out in only water (Table 1, entry 7), the dihydropyridine 5a was isolated instead of final product $\mathbf{4 a}$. The structure of this intermediate was deduced by NMR spectroscopy and HPLC-HRMS spectrometry, concluding that the $\mathrm{Et}_{3} \mathrm{~N}$ not only promotes the formation of $\mathbf{5 a}$, but also favors its final oxidation to afford $\mathbf{4 a}$ (see Fig. S1 and S2, ESI $\dagger$ ).

Once the optimal conditions to obtain 4 a were achieved, we explored a range of benzaldehydes $\mathbf{2} \mathbf{a}-\mathbf{h}$ and aminopyrazoles 3a-e (prepared and available in our $l a b^{23}$ ) in order to test their reactivities and produce the variously substituted IPP $\mathbf{4 a}-\mathbf{x}$. Thus, the reaction under MW conditions for 10-25 min of an equimolar quantity of precursors $\mathbf{1}, \mathbf{2 a}-\mathbf{h}$ and $3 \mathbf{a}-\mathbf{e}$ gave the expected products $\mathbf{4 a - x}$ in good yields. Almost all reactions showed a low electronic effect of the substituent groups on the precursor's reactivity, but longer reaction times are required when less reactive amines are used (e.g., to form the products

Table 1 Reaction condition optimization for the synthesis of $4 a^{a}$

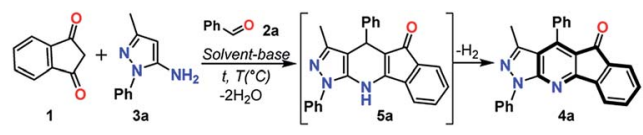

\begin{tabular}{lllll}
\hline Entry & Solvent : base & $T\left({ }^{\circ} \mathrm{C}\right)$ & Time $t$ & Yield [\%] \\
\hline 1 & $\mathrm{H}_{2} \mathrm{O}: \mathrm{Et}_{3} \mathrm{~N}$ & $80^{b}$ & $10 \mathrm{~min}$ & 68 \\
2 & $\mathrm{H}_{2} \mathrm{O}: \mathrm{Et}_{3} \mathrm{~N}$ & $80^{b}$ & $15 \mathrm{~min}$ & 84 \\
3 & $\mathrm{H}_{2} \mathrm{O}: \mathrm{Et}_{3} \mathrm{~N}$ & $100^{b}$ & $15 \mathrm{~min}$ & 83 \\
4 & $\mathrm{H}_{2} \mathrm{O}: \mathrm{Et}_{3} \mathrm{~N}$ & Reflux $^{c}$ & $15 \mathrm{~min}$ & 44 \\
5 & $\mathrm{DMF}: \mathrm{Et}_{3} \mathrm{~N}$ & Reflux $^{c}$ & $24 \mathrm{~h}$ & 60 \\
6 & $\mathrm{EtOH}: \mathrm{Et}_{3} \mathrm{~N}$ & Reflux $^{c}$ & $24 \mathrm{~h}$ & 25 \\
$7^{d}$ & $\mathrm{H}_{2} \mathrm{O}$ & $80^{b}$ & $24 \mathrm{~h}$ & - \\
8 & $\mathrm{EtOH}_{9}$ & $80^{b}$ & $15 \mathrm{~min}$ & 43 \\
9 & $\mathrm{H}_{2} \mathrm{O}: \mathrm{KOH}_{10}$ & $80^{b}$ & $15 \mathrm{~min}$ & 22 \\
& $\mathrm{H}_{2} \mathrm{O}: \mathrm{K}_{2} \mathrm{CO}_{3}$ & $80^{d}$ & $15 \mathrm{~min}$ & 20
\end{tabular}

${ }^{a}$ Reaction conditions: equimolar quantities $(0.25 \mathrm{mmol})$ of $1,2 \mathrm{a}$ and $3 \mathrm{a}$. ${ }^{b}$ Run in $10 \mathrm{~mL}$ sealed tube under MW in $0.7 \mathrm{~mL}$ of solvent $(0.1$ equiv. of base) or a mixture $\mathrm{H}_{2} \mathrm{O}: \mathrm{Et}_{3} \mathrm{~N}(15: 1 \mathrm{v} / \mathrm{v}) .{ }^{c}$ Conventional heating in a solvent : $\mathrm{Et}_{3} \mathrm{~N}$ mixture $(2 \mathrm{~mL}, 15: 1 \mathrm{v} / \mathrm{v}) .{ }^{d}$ A dihydropyridine intermediate was isolated, see ESI. 
4p-x, where amines 3 have electron-withdrawing groups). ${ }^{22,23}$ Moreover, in the reactions using benzaldehydes having electron-donating groups, longer reaction times are required to give the desired products (Scheme 2). The formation of the fused compounds $\mathbf{4 a - x}$ was confirmed by their complete spectral characterization (see Experimental, ESI $\dagger$ ).

Casually, in the reaction using the poorly electrophilic benzaldehyde $2 \mathbf{h}$ under the general conditions by $\mathrm{MW}\left(80^{\circ} \mathrm{C}\right.$ in $\mathrm{H}_{2} \mathrm{O}: \mathrm{Et}_{3} \mathrm{~N}$ for $15 \mathrm{~min}$ ) a different compound was formed $\mathbf{6 h}$. HRMS and NMR analysis confirmed that this product was obtained by the condensation of $\mathbf{1}$ with $\mathbf{2 h}$ without the participation of the respective amine 3a (see Experimental in ESI $\dagger$ ). Subsequent MW reaction of the intermediate $\mathbf{6 h}$ with one equiv. of $3 \mathbf{a}$ (for $15 \mathrm{~min}$ at $80^{\circ} \mathrm{C}$ ) leads to the desired product $4 \mathbf{d}$ in $90 \%$ yield, while a longer reaction time (25 $\mathrm{min}$ ) directly obtain $4 \mathbf{d}$ via the multicomponent reaction (Scheme 3). These results confirm that the synthesis of the IPP $\mathbf{4 a - x}$ proceeds by the intermediate $\mathbf{6 h}$, which then reacts with the amine $\mathbf{3 a}$ with subsequent loss of water and hydrogen molecules, in agreement with previous works. ${ }^{17-20}$ Broadly, this methodology was optimized and successfully tested using various substrates allowing its generality and greener approach.

With the ketones $\mathbf{4 a - x}$ in hand, we carried out Knoevenagel reaction with malononitrile to produce the dicyanovinylidene derivatives 7a-d substituted at position 4 with different donor (D) or acceptor (A) aryl groups. Products 7a-d were prepared in good to excellent yields using an excess of malononitrile in the presence of titanium chloride $\left(\mathrm{TiCl}_{4}\right)$ and pyridine in chlorobenzene at reflux for $24 \mathrm{~h}$ (Scheme 4 ). These reaction conditions are analogous to those reported with fluorenones containing a sterically hindered carbonyl group, ${ }^{36-38}$ such as the structures $\mathbf{4 a}-\mathbf{x}$. Therefore, special reaction conditions were required to

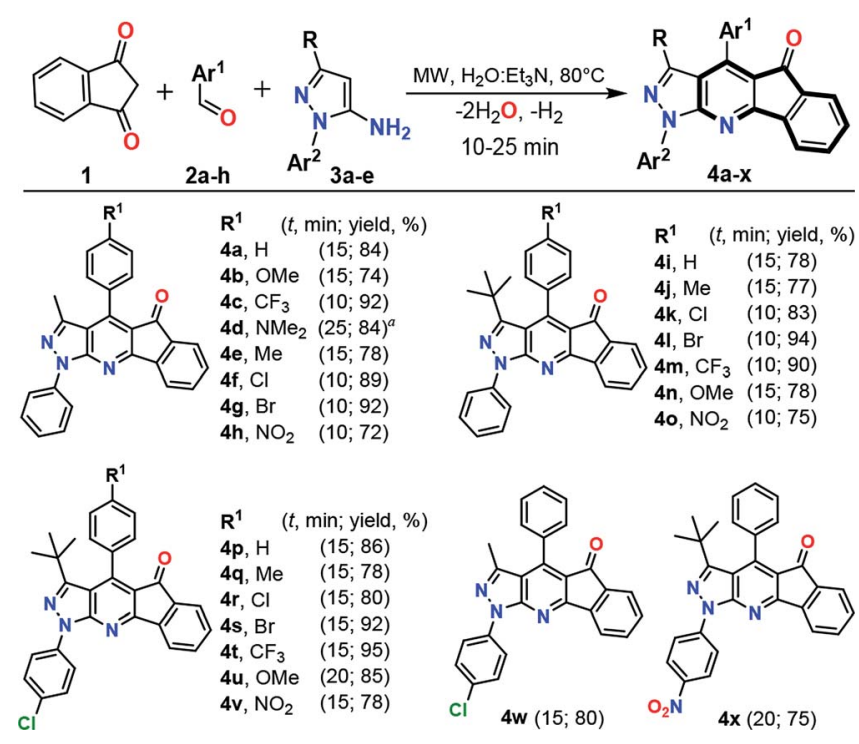

Scheme $2 \mathrm{MW}$-assisted synthesis of pyrazolo-fused 4-azafluorenones $4 a-x$. Reaction conditions: equimolar quantities $(0.25$ $\mathrm{mmol}$ ) of $1,2 \mathrm{a}-\mathrm{h}$ and $3 \mathrm{a}-\mathrm{e}$ in a mixture $\mathrm{H}_{2} \mathrm{O}: \mathrm{Et}_{3} \mathrm{~N}(0.7 \mathrm{~mL}, 15: 1 \mathrm{v} / \mathrm{v})$. Run in $10 \mathrm{~mL}$ sealed tube under MW. ${ }^{a}$ Intermediate $6 \mathrm{~h}$ was isolated after 10 min of reaction; see ESI $\uparrow$ for details.

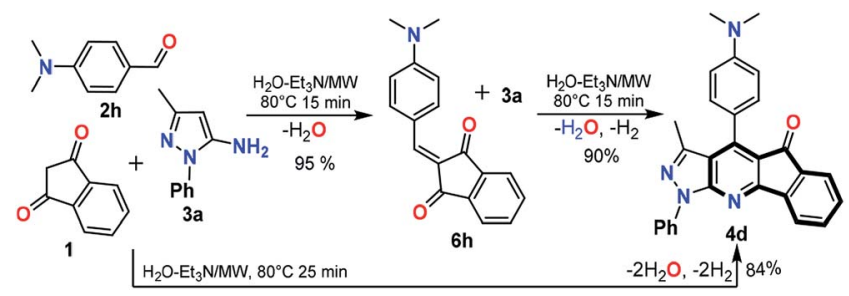

Scheme 3 Synthesis of $4 \mathrm{~d}$ via the intermediate $6 \mathrm{~h}$; see ESI $\uparrow$ for details.

yield compounds 7 a-d since the traditional methods did not work..$^{31,32,39}$ These compounds were synthesized considering the important photophysical properties of pyrazole derivatives ${ }^{22,30-32,40,41}$ and the azafluorenone moiety. ${ }^{42}$ In addition, the dicyanovinylidene is widely used as an acceptor moiety in the design of $\mathrm{D}-\pi-\mathrm{A}$ dyes that exhibit intramolecular charge transfer (ICT) photophysical process. ${ }^{31,43}$ The structures of the products $7 \mathbf{a}-\mathbf{d}$ were determined by HRMS analysis, ${ }^{1} \mathrm{H}$ spectroscopy, and ${ }^{13} \mathrm{C}$ NMR spectroscopy. Recrystallization of the product $7 \mathbf{b}$ from $N, N$-dimethylformamide (DMF) afforded crystals of suitable size and quality for single-crystal X-ray diffraction analysis (Fig. S12, ESI $\dagger$ ). ${ }^{44}$

\subsection{Photophysical studies}

Solvatochromic studies of dicyanovinylidene derivatives 7ad with different electron-donor (D) and electron-acceptor (A) groups were carried out in order to establish if these products can be used as new organic fluorophores (Fig. 2). The UV-vis absorption spectra (Fig. S3†) and fluorescence emission (Fig. 3 and $\mathrm{S} 4 \dagger$ ) were taken in solvents of different polarity such as toluene (PhMe), dichloromethane (DCM), acetone, acetonitrile (ACN), and dimethylsulfoxide (DMSO) at $50 \mu \mathrm{M}$ (Table S1 $\dagger$ ). The UV-vis spectra of 7a-d showed two distinctive absorption bands around 300 and $430 \mathrm{~nm}$, the first can be assigned to transitions $\pi \rightarrow \pi^{*}$ and the second (with the lower intensity) around $430 \mathrm{~nm}$ can be attributed to transitions So $\rightarrow$ intramolecular

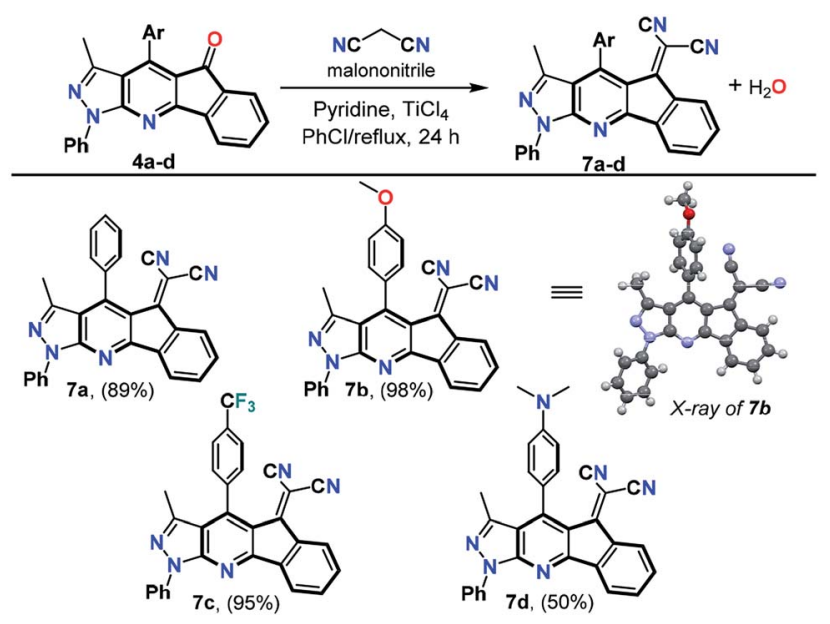

Scheme 4 Synthesis of dicyanovinylidene derivatives $7 a-d$. Reaction conditions: 4a-d (1 equiv.), malononitrile (10 equiv.), pyridine (20 equiv.), and $\mathrm{TiCl}_{4}$ (10 equiv.); see $\mathrm{ESI} \uparrow$ for details. 

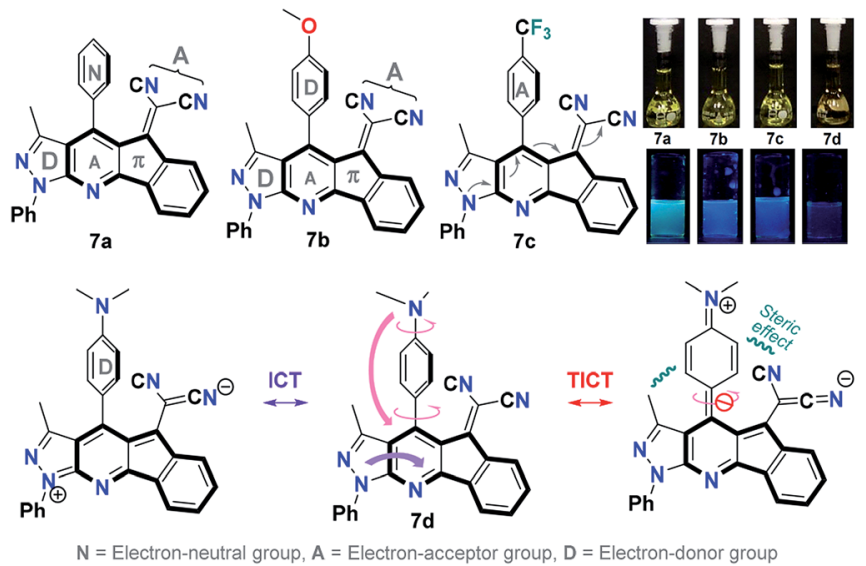

Fig. 2 Structure of $7 a-d$. Photographs were taken using $50 \mu \mathrm{M}$ solutions in DMSO. A hand-held UV lamp under long wavelength $(\lambda=$ $365 \mathrm{~nm}$ ) was used.
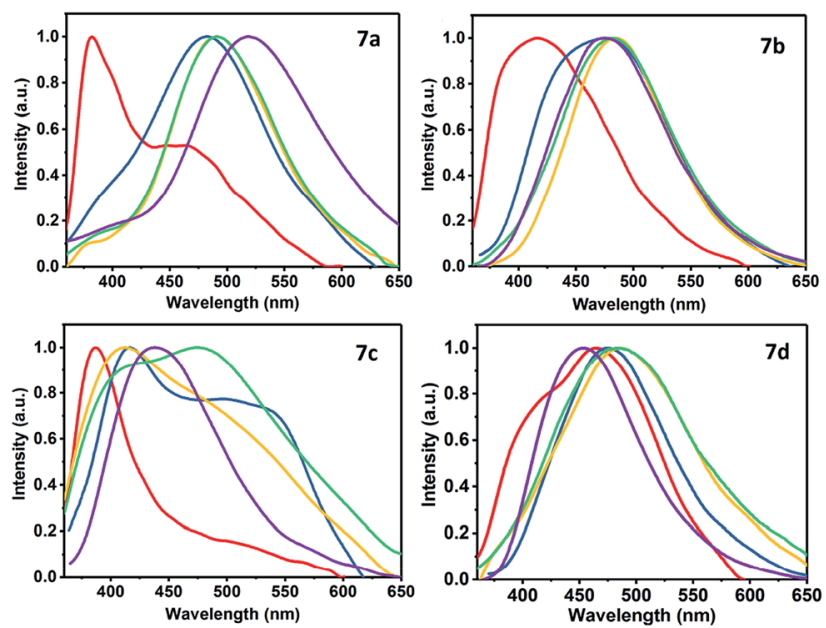

Fig. 3 Normalized fluorescence spectra of $7 a-d$ in different solvents. Red (PhMe), blue (DCM), yellow (acetone), green (MeCN), and purple (DMSO).

charge transfer (ICT). This band is caused by an ICT from the pyrrole-type $\mathrm{N}$ atom of the pyrazolic ring to a $\mathrm{C} \equiv \mathrm{N}$ group, and its intensity reveals a weak ICT effect consistent with its poor solvatochromism in polar solvents (Fig. 2 and S3 $\dagger$ ).

Regarding the emission spectra of $7 \mathbf{a}-\mathbf{d}$, both the quantum yields and fluorescence do not have a significant dependence on the solvent polarity and the 4-aryl group. Products $\mathbf{7 b}$ and $\mathbf{7} \mathbf{c}$ showed a higher fluorescence emission in DMSO and a hypsochromic shift compared with 7a and $\mathbf{7 d .}$ The compound $\mathbf{7 d}$ had the higher fluorescence in acetonitrile with respect to $7 \mathbf{a}-\mathbf{c}$, showing a bathochromic shift. The compound $\mathbf{7 b}$ displayed the highest emission of fluorescence in acetone, whereas in dichloromethane it was the compound 7c. Finally, the use of toluene as a solvent did not show significant fluorescence emission in the heterocycles 7ad (Fig. S4 and Table S1†). Fig. 3 shows the direct effect of the solvent in each of the products $\mathbf{7 a - d}$, where $\mathbf{7 d}$ is the only compound that shows a bathochromic shift as the polarity of the solvent increases. This result indicates that there is a more significant ICT in $\mathbf{7 d}$ due to the strong donor character of the dimethylamino group $\left(\mathrm{NMe}_{2}\right)$ that makes the D$\pi-\mathrm{A}$ system more efficient.

Although 7d exhibited a greater ICT versus 7a-c, the fluorescence emission in DMSO $(\phi=0.002)$ is very low compared to acetonitrile $(\phi=0.181)$. This phenomenon can be the result of a positive solvatokinetic effect that consists in a reduction of the quantum yield due to a high degree of ICT that causes an increase of the speed of non-radiative relaxation of the excited state. ${ }^{45}$ Likewise, a dual emission in the fluorescence spectra was observed mainly in toluene for $7 \mathbf{a}, 7 \mathbf{c}$ and $\mathbf{7 d}$. The first band is assigned to the locally excited state (LE) by ICT processes, while the second to a twisted intramolecular charge transfer (TICT) processes. ${ }^{46}$ These results agree with the structural features of 7a-d, since the TICT phenomena are very sensitive to $\mathrm{D} \rightarrow$ A efficacy and strength, the molecular microenvironment and steric effect between groups near the D-A junction. ${ }^{22}$ The structural relaxation of excited states in weakly polar solvents (reduced interaction with $7 \mathbf{a}-\mathbf{d}$ in its excited state) allows a greater freedom of rotation in the $\mathrm{D}-\mathrm{A}$ junctions, thus offering a dual fluorescence (Fig. 2, 3 and $\mathrm{S} 4 \dagger$ ). ${ }^{22}$

Preliminary UV-vis and fluorescence studies of 7a-d in the presence of different ions were carried out to identify the possible application of these compounds in chemosensors design. From qualitative test of $7 \mathbf{a}-\mathbf{d}$ in acetonitrile with anions, cyanide ion $\left(\mathrm{CN}^{-}\right)$caused a significant change in the absorption and fluorescence emission of $7 \mathbf{a}-\mathbf{d}$. Besides, the fluorescence emission effect by adding different equivalents of $\mathrm{CN}^{-}$to solutions of $7 \mathbf{a}-\mathbf{d}$ in acetonitrile was evaluated (Fig. S10 and S11 and Table S3, ESI $\dagger$ ). From the UV-vis absorption spectra, a decrease of the band round $430 \mathrm{~nm}$ was observed after $\mathrm{CN}^{-}$was added, showing that a nucleophilic addition occurred on the dicyanovinylidene group (Fig. S10†). ${ }^{32}$ The emission spectra of $7 \mathbf{a}-\mathbf{c}$ showed a new band round $620 \mathrm{~nm}$ with an increased fluorescence upon $\mathrm{CN}^{-}$addition (Fig. S11 $\dagger$ ). The increase in quantum yield is 6 times higher after adding 10 equiv. of $\mathrm{CN}^{-}$(Table S3 $\dagger$ ). An exception of this trend occurred with $\mathbf{7 d}$, a decrease in the emission around $550 \mathrm{~nm}$ with a slight bathochromic shift was observed when $\mathrm{CN}^{-}$was added (Fig. S11 $\dagger$ ). After adding 100 equiv. of $\mathrm{CN}^{-}$, it was observed that the quantum yield was 8 times lower compared with the initial fluorescence (Table S3† and Scheme 5).

The preliminary results in $\mathrm{CN}^{-}$sensing showed that $\mathbf{7 d}$, substituted with the $4-\mathrm{Et}_{2} \mathrm{NPh}$ group, is the least reactive of the compounds $7 \mathbf{a}-\mathbf{d}$. Likewise, the regioisomeric addition products 7-CN or $\mathbf{C N - 7}$ could be obtained according to their better stabilization. Possibly, CN-7 is most favored when derivatives $7 \mathbf{7}-\mathbf{c}$ were used since the emission spectra show a high bathochromic shift, which is characteristic for this type of highly-conjugated heteroaromatic anion (Scheme 5 and Fig. S11 $\dagger$ ). The study towards the design of TURN-ON and TURN-OFF sensors based on the structures of $7 \mathbf{a}-\mathbf{d}$ is still ongoing. 

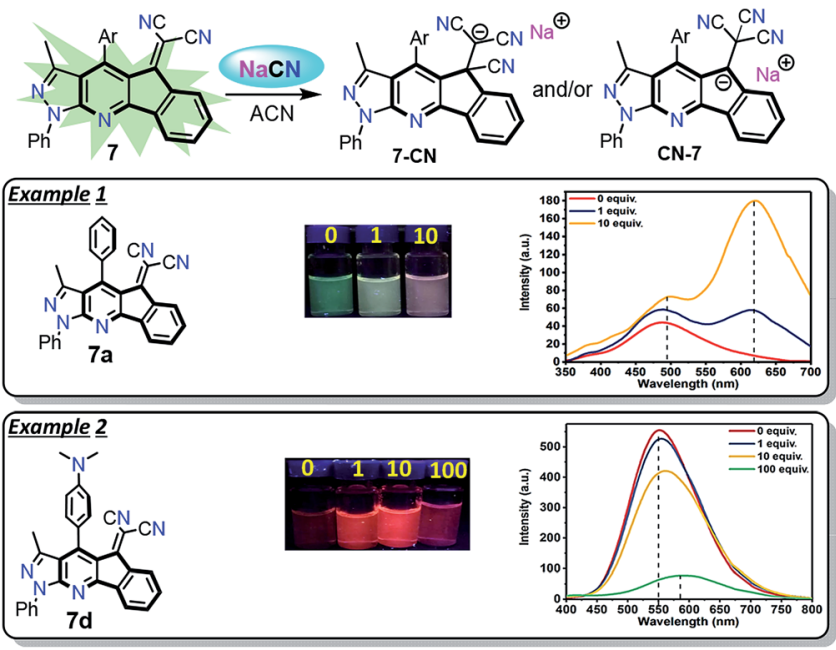

Scheme 5 Fluorescent probes for $\mathrm{CN}^{-}$detection. Solutions $50 \mu \mathrm{M}$ in $\mathrm{ACN}$ with $\mathrm{CN}^{-}$(0 to 100 equiv.). Photograph was taken using a handheld UV lamp $(\lambda=365 \mathrm{~nm})$.

\subsection{Computational calculation}

In order to understand the nature of the electronic transitions present in the compounds 7a-d, TD-DFT calculations were done in gas phase. The $\lambda$ max values were obtained from the theoretical UV-vis spectra with a theory level B3LYP/6-31G (d,p). The maximum calculated UV absorptions, the theoretical electronic excitation energies, the calculated oscillator forces and the electronic gas phase transitions are detailed in Table S2. $\dagger$ The band between 340 and $350 \mathrm{~nm}$ is assigned mainly to the transition HOMO-5 $\rightarrow$ LUMO in 7a, HOMO-1 $\rightarrow$ LUMO in $7 \mathbf{b}$, HOMO $-4 \rightarrow$ LUMO in 7c, and HOMO-5 $\rightarrow$ LUMO in $7 \mathbf{d}$, where it is predicted that these transitions are of nature $\pi \rightarrow$ $\pi *$. According to the diagrams of frontier orbitals of these transitions (Fig. 4 and S5-S9 of ESI $\dagger$ ), the electronic nature of the substituent groups of the aryl ring has a significant influence on the ICT towards the dicyanovinylidene group, where $7 \mathbf{a}$

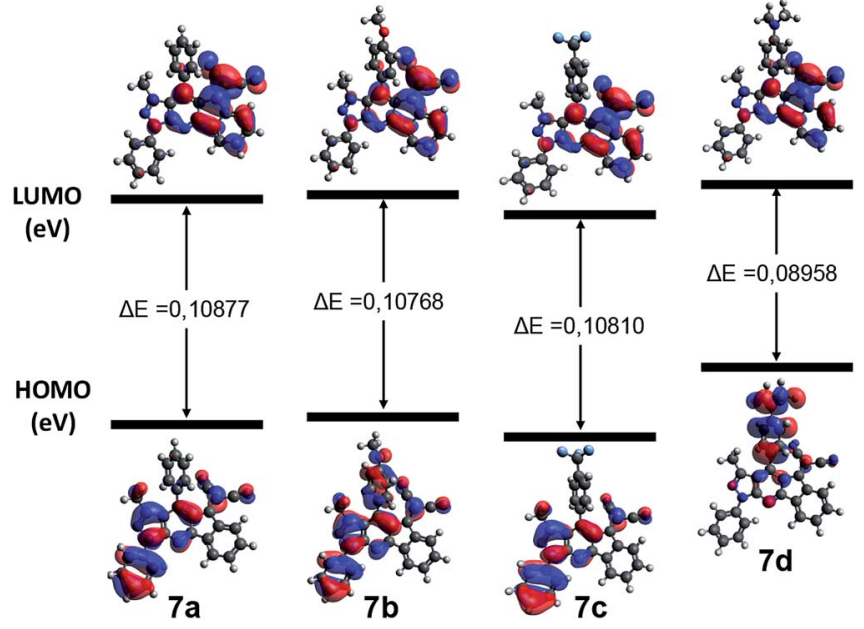

Fig. 4 Frontier orbitals of $7 a-d$ generated using Avogadro. ${ }^{48}$ showed a charge transfer from the 4-phenyl group and the indene moiety.

Compound $\mathbf{7 b}$ is carried out from the $p$-methoxyphenyl group and the phenylpyrazole fragment, while at 7c, this phenomenon occurs from the entire molecule. Finally, for $\mathbf{7 d}$ this CT is favored mainly from the $p$-dimethylaminophenyl group to dicyanovinylidene group, due to the strong donor character of this substituent. The energy levels of the frontier orbitals of compounds 7a-d are illustrated in the Fig. 4. These results showed that an electron withdrawing group such as $\mathrm{CF}_{3}$ could stabilize the energy levels of both the HOMO and LUMO orbitals, due to its inductive effect. On the other hand, electrondonating groups such as $\mathrm{OMe}$ and $\mathrm{NMe}_{2}$, destabilize both border orbitals. ${ }^{47}$ Additionally, comparing the band gap energy $(\Delta E)$ of the compounds $7 \mathbf{a}-\mathbf{d}$, it can be concluded that $7 \mathbf{d}$ has a lower $\Delta E$ due to the strong electron-donor character of the dimethylamino group $\left(\mathrm{NMe}_{2}\right)$ that favors a higher $\mathrm{CT}$, which makes it less reactive towards nucleophilic addition reactions.

\section{Conclusions}

In summary, we have developed a MW-assisted method to promote the three-component synthesis of the attractive synthetic scaffold IPP $\mathbf{4 a - x}$ using diverse starting $N$-arylpyrazoles and $\mathrm{Et}_{3} \mathrm{~N}$ as catalyst. With this green approach using water as a solvent, high yields of all products with short reaction times were obtained. The IPP $\mathbf{4 a - x}$ are of great interest as reagents to prepare important derivatives with biological and optical applications. Thus, novel dicyanovinylidene derivatives 7a-d were synthesized from precursors $4 \mathbf{4}-\mathbf{d}$ and their photophysical properties were studied, which proved that the IPP core is a modular fluorophore acting via an ICT phenomenon. Additionally, preliminary UV-vis and fluorescence spectroscopic studies showed that the products $7 \mathbf{a}-\mathbf{d}$ could be used as fluorescent chemodosimeters for cyanide detection.

\section{Conflicts of interest}

The authors declare no competing financial interest.

\section{Acknowledgements}

We wish to thank the Chemistry Department and Vicerrectoría de Investigaciones from Universidad de los Andes for financial support. We express our gratitude to the Colombian Institute for Science and Research (COLCIENCIAS, Project Code 120465843502). We also wish to tank Edwin Guevara of Universidad de los Andes for acquiring the mass spectra. JC acknowledge to Universidad de Jaén and the Consejería de Economía, Innovación y Ciencia (Junta de Andalucía, Spain), and Centro de Instrumentación Científico-Técnica of the Universidad de Jaén (UJA) and its staff for the data collection.

\section{Notes and references}

1 H. Naeimi and A. Didar, Ultrason. Sonochem., 2017, 34, 889895. 
2 R. Gali, J. Banothu, R. Gondru, R. Bavantula, Y. Velivela and P. A. Crooks, Bioorg. Med. Chem. Lett., 2015, 25, 106-112.

3 M. V. Murlykina, Y. I. Sakhno, S. M. Desenko, S. V. Shishkina, O. V. Shishkin, D. O. Sysoiev, M. N. Kornet, D. Schols, J. L. Goeman, J. Van der Eycken, E. V. Van der Eycken and V. A. Chebanov, Eur. J. Org. Chem., 2015, 2015, 4481-4492.

4 P. Nagender, R. Naresh Kumar, G. Malla Reddy, D. Krishna Swaroop, Y. Poornachandra, C. Ganesh Kumar and B. Narsaiah, Bioorg. Med. Chem. Lett., 2016, 26, 4427-4432.

5 P. Czodrowski, A. Mallinger, D. Wienke, C. Esdar, O. Pöschke, M. Busch, F. Rohdich, S. A. Eccles, M.-J. OrtizRuiz, R. Schneider, F. I. Raynaud, P. A. Clarke, D. Musil, D. Schwarz, T. Dale, K. Urbahns, J. Blagg and K. Schiemann, J. Med. Chem., 2016, 59, 9337-9349.

6 L.-L. Yang, G.-B. Li, H.-X. Yan, Q.-Z. Sun, S. Ma, P. Ji, Z.-R. Wang, S. Feng, J. Zou and S.-Y. Yang, Eur. J. Med. Chem., 2012, 56, 30-38.

7 S. Park, T. M. Kadayat, K.-Y. Jun, T. B. Thapa Magar, G. Bist, A. Shrestha, E.-S. Lee and Y. Kwon, Eur. J. Med. Chem., 2017, 125, 14-28.

8 N. M. Evdokimov, S. Van slambrouck, P. Heffeter, L. Tu, B. Le Calvé, D. Lamoral-Theys, C. J. Hooten, P. Y. Uglinskii, S. Rogelj, R. Kiss, W. F. A. Steelant, W. Berger, J. J. Yang, C. G. Bologa, A. Kornienko and I. V. Magedov, J. Med. Chem., 2011, 54, 2012-2021.

9 J. Chen, W. Liu, J. Ma, H. Xu, J. Wu, X. Tang, Z. Fan and P. Wang, J. Org. Chem., 2012, 77, 3475-3482.

10 A. Sharma, S. Umar, P. Kar, K. Singh, M. Sachdev and A. Goel, Analyst, 2016, 141, 137-143.

11 P. Gunasekaran, S. Perumal, J. C. Menéndez, M. Mancinelli, S. Ranieri and A. Mazzanti, J. Org. Chem., 2014, 79, 1103911050 .

12 B. Jiang, W. Fan, M.-Y. Sun, Q. Ye, S.-L. Wang, S.-J. Tu and G. Li, J. Org. Chem., 2014, 79, 5258-5268.

13 J. Gálvez, J. Quiroga, B. Insuasty and R. Abonia, Tetrahedron Lett., 2014, 55, 1998-2002.

14 J.-C. Castillo and J. Portilla, Targets Heterocycl. Syst., 2018, 22, 194-223.

15 J.-J. Wang, X. Feng, Z. Xun, D.-Q. Shi and Z.-B. Huang, J. Org. Chem., 2015, 80, 8435-8442.

16 J. Quiroga, J. Portilla, H. Serrano, R. Abonía, B. Insuasty, M. Nogueras and J. Cobo, Tetrahedron Lett., 2007, 48, 1987-1990.

17 J. M. Khurana, A. Chaudhary, B. Nand and A. Lumb, Tetrahedron Lett., 2012, 53, 3018-3022.

18 D.-Q. Shi, F. Yang and S.-N. Ni, J. Heterocycl. Chem., 2009, 46, 469-476.

19 D.-Q. Shi, J.-W. Shi and H. Yao, J. Chin. Chem. Soc., 2009, 56, 504-509.

20 J. Quiroga, D. Cobo, B. Insuasty, R. Abonía, S. Cruz, M. Nogueras and J. Cobo, J. Heterocycl. Chem., 2008, 45, 155-159.

21 J. Portilla, C. Lizarazo, J. Cobo and C. Glidewell, Acta Crystallogr., Sect. C: Cryst. Struct. Commun., 2011, 67, 479483.
22 M. García, I. Romero and J. Portilla, ACS Omega, 2019, 4, 6757-6768.

23 A. Charris-Molina, J.-C. Castillo, M. Macías and J. Portilla, J. Org. Chem., 2017, 82, 12674-12681.

24 J.-C. Castillo, J. Orrego-Hernández and J. Portilla, Eur. J. Org. Chem., 2016, 2016, 3824-3835.

25 J. Orrego-Hernández, J. Cobo and J. Portilla, Eur. J. Org. Chem., 2015, 2015, 5064-5069.

26 M. Romain, M. Chevrier, S. Bebiche, T. Mohammed-Brahim, J. Rault-Berthelot, E. Jacques and C. Poriel, J. Mater. Chem. C, 2015, 3, 5742-5753.

27 L. A. Estrada, J. E. Yarnell and D. C. Neckers, J. Phys. Chem. A, 2011, 115, 6366-6375.

28 L. A. Estrada and D. C. Neckers, J. Org. Chem., 2009, 74, 84848487.

29 X.-H. Zhou, Y. Zhang, Y.-Q. Xie, Y. Cao and J. Pei, Macromolecules, 2006, 39, 3830-3840.

30 A. Tigreros, H.-A. Rosero, J.-C. Castillo and J. Portilla, Talanta, 2019, 196, 395-401.

31 J.-C. Castillo, A. Tigreros and J. Portilla, J. Org. Chem., 2018, 83, 10887-10897.

32 J. Orrego-Hernández and J. Portilla, J. Org. Chem., 2017, 82, 13376-13385.

33 J. Orrego-Hernández, N. Nuñez-Dallos and J. Portilla, Talanta, 2016, 152, 432-437.

34 O. N. Petrova, V. V. Lipson, L. L. Zamigailo, M. G. Shirobokova, V. I. Musatov, V. N. Baumer and D. S. Sofronov, Russ. J. Org. Chem., 2015, 51, 1597-1605.

35 A. Chebanov, V. E. Saraev, S. M. Desenko, V. N. Chernenko, I. V. Knyazeva, U. Groth, T. N. Glasnov and C. O. Kappe, J. Org. Chem., 2008, 73, 5110-5118.

36 D. Xia, T. Marszalek, M. Li, X. Guo, M. Baumgarten, W. Pisula and K. Müllen, Org. Lett., 2015, 17, 3074-3077.

37 H. Usta, A. Facchetti and T. J. Marks, Org. Lett., 2008, 10, 1385-1388.

38 A. P. Kadutskii and N. G. Kozlov, Russ. J. Org. Chem., 2006, 42, 1388-1391.

39 X. Yang, T. Fox and H. Berke, Chem. Commun., 2011, 47, 2053-2055.

40 A. C. Götzinger, F.-A. Theßeling, C. Hoppe and T.-J.-J. Müller, J. Org. Chem., 2016, 81, 10328-10338.

41 B. Willy and T.-J.-J. Müller, Org. Lett., 2011, 13, 2082-2085.

42 M. Gao, H. Su, Y. Lin, X. Ling, S. Li, A. Qin and B. Z. Tang, Chem. Sci., 2017, 8, 1763-1768.

43 W. Chen, Z. Zhang, X. Li, H. Agren and J. Su, RSC Adv., 2015, 5, 12191-12201.

44 CCDC 1886021 (7b) contains the supplementary crystallographic data for this paper. $\dagger$

45 S. A. Khan, A. M. Asiri and S. H. Al-Thaqafy, RSC Adv., 2016, 6, 102218-102225.

46 S. Manickam, U. Balijapalli and K. I. Sathiyanarayanan, New J. Chem., 2018, 42, 860-871.

47 W. Wan, H. Wang, H. Lin, J. Wang, Y. Jiang, H. Jiang, S. Zhu, Z. Wang and J. Hao, Dyes Pigm., 2015, 121, 138-146.

48 M. D. Hanwell, D. E. Curtis, D. C. Lonie, T. Vandermeersch, E. Zurek and G. R. Hutchison, J. Cheminf., 2012, 4, 1-17. 